\title{
O Museu Nacional e seu papel na história das ciências e da saúde no Brasil
}

\author{
The National Museum and its role in the history \\ of science and health in Brazil
}

\author{
El Museo Nacional y su papel en la historia de las \\ ciencias y la salud en Brasil
}

\author{
Dominichi Miranda de Sá 1 \\ Magali Romero Sá 1 \\ Nísia Trindade Lima 1
}

doi: 10.1590/0102-311X00192818
"As histórias não são contadas uma vez por todas, para toda a eternidade, mas surgem sempre em função de determinados problemas de orientação temporal, de determinadas épocas e determinados homens” 1 (p. 129).

\section{Introdução}

No domingo, 2 de setembro de 2018, o país foi surpreendido pela notícia de que o Museu Nacional, situado na Quinta da Boa Vista no Rio de Janeiro, estava em chamas. As primeiras imagens foram chocantes; tratava-se de um incêndio de enormes proporções. As notícias eram dilacerantes para profissionais e estudantes da instituição, que celebrava seus dois séculos de existência no mesmo ano do desastre: o acervo de 20 milhões de peças, de valor inestimável para diferentes áreas científicas, como arqueologia, biologia, paleontologia, antropologia física e cultural, etnologia, história e botânica, estava quase inteiramente destruído. O Museu abrigava biblioteca e coleções biológicas e documentais; afrescos; fósseis; artefatos de diferentes sociedades pré-colombianas, ameríndias, indígenas, africanas, egípcias e etruscas. Do seu acervo, constavam o crânio de Luzia, o fóssil humano mais antigo das Américas; o meteorito de Bendegó, descoberto no século XVIII, e muitas outras peças que encantaram gerações de visitantes. O próprio prédio histórico, o Palácio de São Cristóvão, um dos maiores patrimônios culturais do país, ficou em ruínas e mal deteve a sua fachada.

O incêndio no Museu Nacional, instituição de pesquisa, ensino e memória subordinada à Universidade Federal do Rio de Janeiro (UFRJ), abriu enorme debate na opinião pública. Em conjuntura de gravíssima crise política, institucional e econômica no país, o evento suscitou discussões sobre carência orçamentária e de infraestrutura nas universidades públicas, ausência de políticas de cultura e CT\&I no Brasil, modalidades de captação e gestão de recursos na esfera pública, privatização de museus e reforma do Estado. O desastre levou à extinção do Instituto Brasileiro de Museus (Ibram) e à criação da Agência Brasileira de Museus (Abram) em clara reorientação da política federal para as instituições de memória e cultura. Um dos pontos cruciais do debate público era a pergunta: como entes federativos e sociedade brasileira permitiram que parte importante da simbologia e materialidade da história nacional fosse completamente destruída?

Quais memória e história institucionais são possíveis depois do trauma? O historiador da ciência David Knight 2 chamou a atenção de que é impossível colocar questões ao passado sem fontes ao
1 Casa de Oswaldo Cruz, Fundação Oswaldo Cruz, Rio de Janeiro, Brasil.

\section{Correspondência}

D. M. Sá

Centro de Documentação e

História da Saúde, Casa de

Oswaldo Cruz, Fundação

Oswaldo Cruz.

Av. Brasil 4365, CDHS,

sala 226, Rio de Janeiro, $R J$

21040-900, Brasil.

dominichi.de.sa@gmail.com 
discutir a enorme diferenciação de documentos que concorrem para a construção de uma história. Como o acervo de coleções biológicas e documentais do Museu Nacional foi destruído, não será mais possível a história de sua importância para a comunidade científica nacional? O Museu Nacional desaparecerá definitivamente e será esquecido? Esse artigo visa refletir sobre essas perguntas, sem negar, no entanto, as perdas irreparáveis do acervo do Museu mais antigo e popular do Brasil.

\section{Um museu de muitos tempos}

Foram inúmeras as manifestações de solidariedade e pesar, nacionais e internacionais, de homens públicos e institucionais, pelo incêndio. Apesar das origens variadas das notas divulgadas pela imprensa, nelas, o Museu pareceu restringido à memória das famílias real portuguesa e imperial que residiram no Palácio de São Cristóvão. O Museu e o acervo, que o casario em São Cristóvão abrigou, tiveram, no entanto, uma trajetória que não é a mesma do Palácio nem é exclusiva da Monarquia ou do Império. Sua história, ao contrário, é a da própria formação do Brasil como nação independente e soberana. E, como veremos, essa história é ainda indissociável da própria história da pesquisa científica no país. Se o prédio, construído originalmente em 1803 como casarão residencial, foi adaptado em 1808 para receber a família real portuguesa e figurou, nas décadas seguintes, como residência da família imperial, o Museu e o acervo tiveram sua origem na antiga Casa de História Natural, mais conhecida como Casa dos Pássaros, criada em 1784 e que abrigava produtos de mineralogia, artefatos indígenas e aves empalhadas. A Casa foi transformada em Museu Real em 1818, constituindo a primeira instituição científica fundada pela corte portuguesa na capital do Reino Unido de Portugal, Brasil e Algarves.

A criação da instituição, que ficaria sediada no Campo de Santana no Rio de Janeiro até 1892, coincidia com movimento intenso de naturalistas estrangeiros em direção ao Reino do Brasil e com a valorização de estudos práticos de história natural para o conhecimento das riquezas da América Portuguesa 3,4,5. As coleções de pesquisa e de exposição do Museu começaram a se formar logo após o Decreto Real de 1818, e, desde então, não pararam de crescer, inclusive porque, já em 1820, a instituição passou a apoiar viagens de exploração científica por diversas partes do Reino.

Com a Independência do Brasil do Reino de Portugal, em 1822, a denominação do Museu foi alterada para Imperial e Nacional. Nessa mesma ocasião, o então Secretário do Estado dos Negócios do Reino e Estrangeiros do Império de Pedro I, o mineralogista José Bonifácio de Andrada e Silva, aproveitando o fato de grande número de naturalistas estrangeiros estarem chegando ao país, propôs que esses viajantes enviassem objetos de história natural ao Museu, e, em troca, oferecia facilidades e proteção em suas expedições. O Museu criou ainda, em 1824, um laboratório químico que fazia pesquisas médicas e mineralógicas, e suas dependências serviram aos alunos das escolas superiores de engenharia e medicina da Corte e do Colégio Pedro II 6.

Um precioso acervo mineralógico, etnográfico, zoológico e botânico foi gradualmente sendo formado a partir de 1822. Pesquisadores estrangeiros começaram a colaborar diretamente com a instituição, pois a indicação governamental era a de que o Museu fosse "universal", ou seja, ele deveria possuir coleções com objetos que representassem o mundo inteiro. Intercâmbios internacionais trouxeram ao acervo peças etnográficas e arqueológicas, produtos mineralógicos e coleções ornitológicas, instrumentos de física e química, pinturas e modelos de máquinas industriais de diferentes países 3,4,5.

Inicialmente, o Museu contava apenas com um diretor e um ajudante para tratamento de todo o material científico que recebia. Em 1842, um novo regulamento reorganizou a instituição em seções de Anatomia Comparada e Zoologia; Botânica, Agricultura e Artes Mecânicas; Mineralogia, Geologia e Ciências Físicas; Numismática, Artes Liberais, Arqueologia, Usos e Costumes das Nações Antigas e Modernas 7. Essa reorganização contribuiu para o aumento de estudos de diferentes especialidades, já que, para cada uma delas, havia um naturalista responsável. Em 1856, o Museu passou a realizar conferências públicas sobre antropologia, agricultura, botânica, física e zoologia. Entre 1856 e 1858 , o Museu sofreu reformas, passou a contar com novas salas de visitação abertas ao público às quintasfeiras e recebeu a doação de uma coleção de 2 mil peças de animais marinhos 5 .

Foi ainda nesse período que ocorreu a primeira expedição científica brasileira, a Comissão Científica de Exploração (1859-1861), organizada pelo Instituto Histórico e Geográfico Brasileiro e 
composta por naturalistas do Museu Nacional para a ampliação das coleções nacionais de história natural em botânica, geologia, mineralogia, zoologia, astronomia, etnografia e geografia. A Comissão percorreu as províncias do Ceará, Pernambuco, Piauí, Rio Grande do Norte e Paraíba. O acervo do Museu se diversificou enormemente com os trabalhos de coleta e sistematização dessa Comissão 4.

Em 1863, a instituição inaugurou sua biblioteca. Na década de 1870, ocorreu uma nova reorganização sob a direção do botânico Ladislau Netto, com maior ênfase em atividades de divulgação científica e pesquisa médica. Nesse período, em 1876, também foi criado um periódico científico para divulgar os trabalhos produzidos pelos pesquisadores da casa, os Archivos do Museu Nacional. Houve ainda a criação do cargo de naturalista viajante que incorporou à instituição cientistas estrangeiros que moravam no Brasil. A produção científica e o conhecimento da biodiversidade do país foram expandidos. Grupos ainda não estudados passaram a ser trabalhados em relação à taxonomia, à biologia, aos aspectos evolutivos e à teoria de seleção natural.

Em 1880, um Laboratório de Fisiologia Experimental foi inaugurado no Museu com agenda de estudos sobre veneno de animais, propriedades tóxicas e terapêuticas de plantas, doenças de animais e seres humanos, como beribéri, tuberculose e febre amarela, e fisiologia do cérebro por meio do estudo de primatas. O laboratório era frequentado por profissionais e estudantes da Faculdade de Medicina do Rio de Janeiro e, em fins da década de 1880, priorizava estudos em bacteriologia e de doenças animais 8 .

Nesses mesmos anos, novas áreas foram desenvolvidas na instituição, como paleontologia, antropologia, etnologia e anatomia comparada. Além das conferências e palestras, cursos públicos passaram a ser oferecidos, com uso de material didático variado, murais e projetor de imagens 9 . Uma Exposição Antropológica foi inaugurada em 1882, tendo sido celebrada como verdadeira "festa científica popular" 10.

Com a Proclamação da República, em 1889, o Museu passou a se chamar Nacional e, então, em 1892, finalmente, sua sede e acervo foram transferidos para a Quinta da Boa Vista, e, a esse último, se somaram as peças que as famílias real e imperial tinham reunido no Palácio de São Cristóvão. Em 1899, regulamentou-se o funcionamento de um Horto Botânico, e, na virada do século, as exposições foram franqueadas à visitação às quintas, sábados e domingos. Na primeira década do século $\mathrm{XX}, \mathrm{o}$ Museu passou a contar com três novos laboratórios: química vegetal, entomologia agrícola e fitopatologia, e ampliou a visitação pública: estava aberto diariamente, exceto às segundas, das $8 \mathrm{~h}$ às $17 \mathrm{~h}$.

A despeito da diversificação dos setores de ensino e pesquisa na instituição, a formação de coleções, no entanto, enfrentava sérios limites à época, pois o cargo de naturalista viajante havia sido extinto com a República. O então diretor do Museu, João Batista de Lacerda, chamava constantemente a atenção do poder público para a importância das atividades de campo, que incluíam o estudo e a coleta de material científico, e constituíam as atividades prioritárias em uma instituição de história natural. Lacerda inseria seus argumentos de engrandecimento do Museu no projeto de construção da nação, assinalando que "se queremos tornar indiscutível a hegemonia do Brasil na América do Sul, devemos encarar essa politica também do ponto de vista de superioridade dos nossos recursos intelectuais, e dos nossos institutos de ensino e de ciência" 11 (p. 34).

Em 1907, o Museu Nacional foi, então, convidado a participar da Comissão de Linhas Telegráficas Estratégicas do Mato Grosso ao Amazonas, mais conhecida como Comissão Rondon, com o objetivo de inventariar e estudar a fauna e a flora da região percorrida, assim como o de ser o fiel depositário de todo o material de história natural, arqueologia e etnografia coletado. A incorporação de naturalistas do Museu à Comissão significou a revitalização da instituição, por meio do enriquecimento substancial de seu acervo por meio de coleções obtidas em regiões não visitadas por pesquisadores brasileiros, ou mesmo completamente inexploradas 12. Nas palavras de Alípio de Miranda Ribeiro, zoólogo e um dos membros da comissão, as coleções reunidas fizeram mais pelo Museu Nacional do que tudo que tinha sido realizado em 100 anos de existência da instituição 13.

Os trabalhos de campo duraram de 1907 a 1915, e, além de Miranda Ribeiro, ainda participaram da Comissão os botânicos Alberto Sampaio e Frederico Hoehne, assim como o antropólogo Edgard Roquette-Pinto. Entre os anos de 1908 e 1916, foram depositados no Museu, oriundos das viagens da Comissão Rondon, 8.837 espécimes botânicos, 5.637 espécimes zoológicos, 42 exemplares geológicos, mineralógicos e paleontológicos e 3.380 peças antropológicas 13,14 . Além da relevância das coleções zoológicas e botânicas reunidas, ressalte-se o impacto que elas tiveram para o conhecimento da 
fauna, da flora e da fito e zoogeografia das regiões percorridas, como, por exemplo, as especificidades do cerrado mato-grossense e sua diferenciação das caatingas no Nordeste 12 .

O antropólogo Roquette-Pinto foi diretor do Museu Nacional de 1926 a 1935, e, na sua gestão, a instituição assumiu forte caráter educativo. Uma filmoteca foi criada em 1910, e novas exposições foram inauguradas em 1914, com a intenção de aumentar a visitação pública ao Museu Nacional. Para orientar e facilitar as visitas, a instituição preparou o Guia das Coleções de Antropologia do Museu Nacional: um pequeno manual com os fundamentos gerais da antropologia, e que utilizava os objetos em exposição no Museu como ilustrações às explicações. A partir do seu exemplo, seguiram-se outros guias como o de Arqueologia e o de Geologia do Brasil 15,16.

Sob a sua direção e com a colaboração dos colegas Cândido de Mello Leitão, Heloísa Alberto Torres, Bertha Lutz e Alberto Betim Paes Leme, o Museu incentivava a criação de gabinetes de história natural nas escolas. A proposta era a de que as coleções científicas fossem criadas pelas próprias crianças, que coletariam, tratariam e desenhariam plantas e animais.

Roquette-Pinto fundou, em 1927, o Serviço de Assistência ao Ensino e inaugurou, em 1928, um auditório equipado para aulas de história natural, com projetor de slides e de filmes, onde ocorriam cursos e conferências. Com farta exibição de guias e pôsteres didáticos, que resumiam tópicos para sala de aula e filmes científicos, intentava-se fazer da instituição um museu escolar. Para Roquette-Pinto, o Museu deveria ser "a universidade do povo" 17.

\section{O futuro do Museu Nacional}

Em 1946, o Museu Nacional passou a ser uma das unidades da, então, recém-criada Universidade do Brasil, futura UFRJ. Nas décadas seguintes, novas seções e departamentos foram criados, e o Museu passou a abrigar vários centros de referência no mundo, como o Programa de Pós-graduação em Antropologia Social. Era visitado, anualmente, por milhares de pessoas, especialmente das periferias da cidade, pela facilidade do acesso por trem, ônibus e metrô. As condições de manutenção das exposições e do prédio histórico, no entanto, eram dramáticas, e o incêndio ocorreu.

Como vimos, o Museu teve uma história de dinamização frequente de suas áreas de pesquisa e demais atividades, como o ensino e a visitação pública. Sua marca histórica, como instituição científica de excelência, portanto, não foi suprimida com as chamas. A memória institucional pode mesmo ser preservada graças às análises históricas já disponíveis, e que, em parte, referenciaram esse texto, para compreender tanto a importância de suas agendas de pesquisa e recursos humanos quanto o valor de seu acervo para diferentes áreas do conhecimento científico. Por ter se orientado preferencialmente por essas linhas epistemológicas, a história das ciências e da saúde, em particular, tem a possibilidade de evitar a morte completa da memória do Museu Nacional com a ampla divulgação da sua produção científica sobre a instituição. Além disso, a advertência de João Batista de Lacerda aos poderes públicos no século XIX, sobre a missão institucional desde os primeiros anos de sua existência, ainda tem incrível atualidade e merece ser repetida: um projeto nacional tem toda a relação com a priorização de suas instituições de pesquisa e ensino.

Como ensina o historiador alemão Jörn Rüsen 1, memória e história são constantes antropológicas, ou seja, consciências constitutivas do agir humano para orientação temporal e atribuição de sentidos, especialmente em momentos de crise. Por sua capacidade de estabelecer conexões entre diferentes estratos temporais, à história, especialmente, cabe a defesa constante da utopia. O futuro aqui reivindicado do Museu Nacional é possível a partir da divulgação de seus inestimáveis trabalhos no passado que durou 200 anos. Novas memória e história institucionais não evitarão o trauma nem mitigarão as perdas, o Museu, de fato, é irrecuperável, mas podem servir como vias de resistência a projetos que queiram, no seu lugar, criar centros culturais em nada reverentes à trajetória da Casa dos Pássaros onde tudo começou. 


\section{Colaboradores}

D. M. Sá contribuiu com a formulação do argumento, redação do texto e revisão final do artigo. M. R. Sá e N. T. Lima contribuíram com a formulação do argumento e redação do texto.

\section{Referências}

1. Rüsen J. Razão histórica. Teoria da história: os fundamentos da ciência histórica. Brasília: Editora da UnB; 2001.

2. Knight D. Background and foreground: getting things in context. Br J Hist Sci 1987; 20:3-12.

3. Figueirôa SFM. As Ciências Geológicas no Brasil: uma história social e institucional, 1875-1934. São Paulo: Editora Hucitec; 1997.

4. Lopes MM. O Brasil descobre a pesquisa científica: os museus e as ciências naturais no século XIX. São Paulo: Editora Hucitec; 1997.

5. Museu Real. Dicionário histórico-biográfico das ciências da saúde no Brasil (1832-1930). http://www.dichistoriasaude.coc.fiocruz. $\mathrm{br} / \mathrm{iah} / \mathrm{pt} / \mathrm{pdf} / \mathrm{musnac} . \mathrm{pdf}$ (acessado em 30/ Set/2018)

6. Lacerda JB. Fastos do Museu Nacional do Rio de Janeiro: recordações históricas e scientificas fundadas em documentos authenticos e informações veridicas. Rio de Janeiro: Imprensa Nacional; 1905.

7. Netto L. Investigações históricas e scientificas sobre o Museu Imperial e Nacional do Rio de Janeiro: acompanhadas de uma breve noticia de suas collecções e publicadas por ordem do Ministerio da Agricultura. Rio de Janeiro: Instituto Philomatico; 1870.

8. Gomes ACV. Uma ciência moderna e imperial: a fisiologia brasileira no final do século XIX (1880-1889). Rio de Janeiro: Editora Fiocruz/ Campina Grande: Editora da Universidade Estadual da Paraíba/Belo Horizonte: Fino Traço Editora; 2013.

9. Sá MR, Domingues HMB. O Museu Nacional e o ensino das ciências naturais no Brasil no século XIX. Revista da Sociedade Brasileira de História da Ciência 1996; (15):79-88.
10. Leitão CM. A biologia no Brasil. São Paulo: Companhia Editora Nacional; 1937. (Brasiliana, Série 5ă, volume 99).

11. Bicalho ML. A personalidade de João Batista de Lacerda. In: Museu Nacional, editor. João Batista de Lacerda: comemoração do centenário de nascimento, 1846-1946. Rio de Janeiro: Museu Nacional; 1946. p. 14-40.

12. Sá DM, Sá MR, Lima NT. Telégrafos e inventário do território no Brasil: as atividades científicas da Comissão Rondon (1907-1915). Hist Ciênc Saúde-Manguinhos 2008; 15:779-810.

13. Ribeiro AM. A Comissão Rondon e o Museu Nacional. Rio de Janeiro: Ministério da Agricultura; 1945 .

14. Mello-Leitão C. História das expedições científicas no Brasil. São Paulo: Companhia Editora Nacional; 1941.

15. Lima NT, Sá DM, organizadoras. Antropologia brasiliana: ciência e educação na obra de Edgard Roquette-Pinto. Belo Horizonte: Editora UFMG/Rio de Janeiro: Editora Fiocruz; 2008.

16. Duarte RH. A biologia militante: o Museu Nacional, especialização científica, divulgação do conhecimento e práticas políticas no Brasil (1926-1945). Belo Horizonte: Editora UFMG; 2010.

17. Roquette-Pinto E. Notas e opiniões. Jornal do Brasil 1953; 7 fev. 